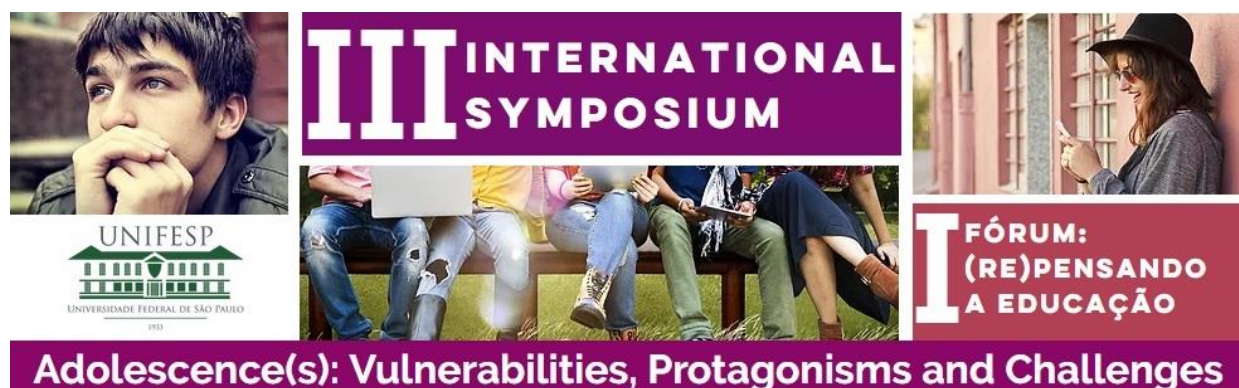

\title{
ARCHITECTURE EDUCATION
}

\section{ARQUITETURA DA EDUCAÇÃO}

\section{Rafael Diedrich Moreira do Amaral ${ }^{1}$}

1. aluno do curso de mestrado em educação da Universidad de la Empresa - Uruguay

E-mail: rdm_amaral@hotmail.com

*Trabalho de conclusão do mestrado scritu sensu de Educação - UDE Uruguay)

*Orientadora; Dra. Patricia Lupion Torres PUC Curitiba

E-mail: patorres@terra.com.br

\section{Como citar:}

AMARAL, Rafael Diedrich Moreira do. Architecture education. In: INTERNATIONAL SYMPOSIUM ADOLESCENCE(S) \& FÓRUM (RE)PENSANDO A EDUCAÇÃO, 3, 2017, São Paulo. Anais... São Paulo: Unifesp, 2017. p.66-73.

DOI: http://dx.doi.org/10.22388/2525-5894.2017.06

Resumo: A arquiteto busca saber do distanciamento entre o ser humano e os meios em que vive atuando de forma pluridisciplinar e realizando assim uma exegese para então reformular o espaços, tornando-os confortáveis e contextualizados com a realidade do homem da atualidade. O docente assim como o arquiteto reconhece a distância entre ele e o aluno?; trazendo consigo embasamento cultural, filosófico, estrutural para construir sua aula, analisar seus alunos, a cultura em que vivem pois hoje existe a necessidade dos professores se contextualizarem com os alunos diante da distância que os separam.

Palavras-Chave: Arquitetura. Distanciamento. Docente. Discente.

Abstract: The architect seeks to know the distance between the human being and the means in which he lives acting in a multidisciplinary way and thus performing an exegesis to reformulate the spaces, making them comfortable and contextualized with the reality of man today. The teacher as well as the architect recognizes the distance between him and the student ?, bringing with it cultural, philosophical, structural basis to build his class, analyze his students, the culture in which they live, since today there is a need for teachers to contextualize with students in front of the distance that separates them.

Keywords: Architecture. Distancing. Teacher. Student.

\section{INTRODUÇÃO}

Dados do Censo de 2010 realizado pelo Instituto Brasileiro de Geografia e Estatística (IBGE) demonstram que houve um crescimento no número de brasileiros com graduação universitária na última década. O percentual geral aumentou de 4,4\% em 2000 para 7,9\% em 2010.

A educação no Brasil vem crescendo de forma gradativa como mostra os dados do IBGE, no entanto, apesar deste crescimento gradativo, apenas oito por cento da população possui nível superior, são profissionais graduados de diversos setores, e toda a classe de 
pedagogos está incluída nesta privilegiada parcela da população diplomada. Muitos destes pedagogos se formam e são absolvidos pelo mercado de trabalho em escolas de educação infantil, ensino fundamental um, sendo do setor público ou privado estes professores passam a ter contato direto com diversas crianças ao menos cinco dias por semana, contato este que precisa ser moldado em contextualização como disse Pestalozzi, que elaborou sua proposta pedagógica baseada em Rousseau (1712-1778) a concepção da educação como processo que deve seguir a natureza e os princípios como da liberdade, da bondade inata do ser e da personalidade individual de cada criança. Libâneo (1991, p. 61), ao analisar as ideias mais importantes de Rousseau, destaca:

1) A preparação da criança para a vida futura deve basear-se no estudo das coisas que correspondem às suas necessidades e interesses atuais. Antes de ensinar as ciências, elas precisam ser levadas a despertar o gosto pelo seu estudo. Os verdadeiros professores são a natureza, a experiência e o sentimento. $\mathrm{O}$ contato da criança com o mundo que a rodeia é que desperta o interesse e suas potencialidades naturais.

2) A educação é um processo natural, ela se fundamenta no desenvolvimento interno do aluno. As crianças são boas por natureza, elas têm uma tendência natural para se desenvolverem.

Existe um distanciamento entre todos os seres humanos, este distanciamento precisa ser reduzido com elementos tirados da realidade conforme diz Pestalozzi (apud MANACORDA 1989, p. 264):

O vivo estímulo da curiosidade provoca tentativas que, se têm êxito positivo ou são encorajadas por outros, levam ao hábito de pensar. Deve-se agir sobre a mente das crianças com elementos tirados da realidade e não com regras abstratas, e se deve ensinar mais com a ajuda de objetos do que de palavras. Este estudo irá pesquisar na linha de saberes e práticas educativas se os docentes reconhecem a existência de um distanciamento entre eles e seus alunos e se eles conhecem e utilizam métodos empíricos ou científicos para medir este distanciamento para que quando reconhecidos aplicar aulas que os contextualizem com seus alunos.

Será utilizando a palavra arquitetura exclusivamente como conceito etimológico, apresentando os conceitos do que é arquitetura com as afirmações de que o arquiteto representa a arte de construir esteticamente e funcionalmente estruturas com embasamento cultural, filosófico, estrutural, se tornando uma ciência pluridisciplinar.

Segundo Alberto Pérez-Gómez, "nos Dez Livros de Arquitetura de Vitrúvio, único tratado de arquitetura conhecido da Roma Antiga, se afirma categoricamente que a função do arquiteto é claramente pluridisciplinar." (PÉREZ-GOMEZ, 1994). 
Para que se atue de forma pluridisciplinar se faz necessário obter embasamento em profundidade de conteúdos e buscar recursos para realizar uma "exegese" sociocultural, exegese do grego $\dot{\varepsilon} \xi \dot{\eta} \gamma \eta \sigma ı \varsigma$ de $\dot{\varepsilon} \xi \eta \gamma \varepsilon \tilde{\imath} \sigma \theta \alpha$ "levar para fora", é o estudo dos antecedentes históricos e culturais do autor, do texto ou de seu público original para interpretação e aplicação da hermenêutica.

Para solidificar a utilização do termo arquitetura podemos ainda citar mestre da arquitetura moderna, o arquiteto franco-suíço Le Corbusier, que afirmou:

"A arquitetura é um fato de arte, um fenômeno de emoção, fora das questões da construção, além delas. A construção é para sustentar; a arquitetura é para emocionar". (CORBUSIER, 1989, p. 10).

O cuidado a ser tomado é o de transformar as práticas educativas em conhecimento finito, onde já não é possível arquitetar estica e tecnicamente algo novo dentro de salas de aula, a linguagem interpretativa não pode ser um fim em si mesma, mas deve-se haver reconstrução pedagógica a medida que somos afetados diante das situações.

Como assinala Ricoeur, a unidade mínima da dialética do sentido e da referência, que é índice da relação entre a linguagem e a condição ontológica do ser-no-mundo. Segundo Ricoeur (2000, p. 32):

[...] a linguagem não é um mundo próprio. Nem sequer é um mundo. Mas, porque estamos no mundo, porque somos afetados por situações e porque nos orientamos mediante a compreensão em tais situações, temos algo a dizer, temos a experiência para trazer à linguagem.

A arquitetura coopera ao revelar a sua relevância e conceituação diante da sociedade, um conhecimento que tomou a cidade de tal forma que passou a fazer parte da nossa relação com o meio, sem arquitetura, a estética não estará tão presente em nosso cotidiano, o processo de formação de mundo pensado a luz da arquitetura possui profundos traços.

Pensar no lugar ocupado pela arquitetura no processo de formação do mundo moderno e, em especial, na sua importância na educação do corpo, parece ser urna tarefa necessária. As transformações do capitalismo, evidenciando seu paralelo material, revelam mudanças nunca antes vistas na forma de conceber, construir, estruturar e organizar a cidade. Espaços, decorações, distribuições e morfologias da arquitetura acentuam a importância de sua dimensão ideológica e simbólica e permitem, assim, pensar por exemplo na organização curricular das escolas e perceber que a ausência de determinado conhecimento ou modos como outros conhecimentos são apresentados têm o seu correspondente direto dado pela organização do espaço, pela construção, pela arquitetura (ZARANKIN, 2002). 
Paul Ricoeur estabelece uma forte relação entre arquitetura e narratividade, trazendo a relevância comparativa da arquitetura como estrutura essencial nos espaços, bem como a narrativa na tempo.

Ricoeur (2002) sugere que há uma relação entre o tempo narrado e o espaço construído, entre arquitetura e narratividade, "a arquitetura está para o espaço como a narrativa está para o tempo, a saber, como operação configurante" (RICOEUR, 2002, p. 44).

O objetivo desta dissertação não é analisar as obras nem os escritos dos arquitetos, nem mesmo apresentar em profundidade conhecimento da escola da arquitetura, já que não temos o conhecimento técnico necessário para essa tarefa, mas apenas trazer etimologicamente a palavra arquitetura para alinhar seu conceito com o distanciamento entre docentes e seus alunos, expondo opiniões de filósofos não-arquitetos sobre a arquitetura.

Segundo Carvalho (2002, p. 70), "Pensar em respostas educativas da escola é pensar em sua responsabilidade para garantir o processo de aprendizagem para todos os alunos, respeitando-os em suas múltiplas diferenças.”.

Segundo Aristóteles, existem quatro causas de movimento: material, formal, motora e final (ARISTÓTELES, 2012, M, 983a-983b). Quando se pergunta pelo fundamento da beleza, é possível escolher uma delas. O consumidor deriva a beleza da causa final, pois ele prioriza a acessibilidade (a forma tátil): a obra é bela se ela é útil (funcional). Já o produtor vincula a beleza à causa formal, pois ele prioriza a configuração (a forma visual): a obra é bela se ela é ordenada (perfeita). O proprietário enxerga a beleza na causa motora, pois ele prioriza a resistência (a matéria tátil): a obra é bela se ela é sólida (durável). O mercador atribui a beleza à causa material, pois ele prioriza a extensão (a matéria visual): a obra é bela se ela é grande (valiosa).

A causa final está vinculada à formal (pois a forma tátil está ligada à forma visual) e a causa motora está vinculada à material (pois a matéria tátil está ligada à matéria visual). Mas a filosofia não examina apenas os fundamentos objetivos da arte: ela deve encontrar também um fundamento subjetivo para explicar o prazer estético. Esse fundamento precisa residir numa das faculdades do sujeito: sentir, desejar, agir, conhecer. É inútil observar que toda percepção estética exige o emprego dessas quatro faculdades: na prática, os filósofos e educadores acabam adotando somente uma ou duas em seus sistemas. $\mathrm{O}$ consumidor vincula a arte à faculdade de sentir, pois explica a beleza a partir dos efeitos que o objeto suscita no sujeito: a obra de arte constitui a forma objetiva de um conteúdo subjetivo, um complemento inorgânico do orgânico.

Essa perspectiva emerge nas estéticas da vida, do sentimento e da funcionalidade. $\mathrm{O}$ mercador vincula a beleza à faculdade de desejar, pois considera o objeto uma sublimação de uma aspiração do sujeito: a obra de arte expressa aquilo que o homem não possui. Essa 
perspectiva se manifesta nas estéticas da vontade e do poder. $\mathrm{O}$ produtor vincula a arte à faculdade de agir, pois ele explica a beleza a partir dos efeitos que o sujeito inscreve no objeto: a obra de arte é a cópia de um pensamento. Essa perspectiva surge nas estéticas da ideia, da forma e da luz. O proprietário vincula a arte ao conhecer, pois ele explica a beleza a partir do conhecimento técnico encerrado no objeto: a obra de arte expressa o domínio do homem sobre a natureza. Essa perspectiva aparece nas estéticas do conhecimento e da compreensão.

As perspectivas (produtor, consumidor, proprietário, mercador) não determinam apenas a escolha da causa objetiva da beleza (formal, final, motora, material) e da faculdade subjetiva para avaliá-la (agir, sentir, conhecer, desejar), mas impregnam igualmente as categorias mais abstratas da filosofia. A polaridade material entre o eu e o não-eu é o fundamento da polaridade ideal entre o ser e o não-ser.

Ora, na arquitetura, o ser é o volume, e o não-ser é o vazio. Do ponto de vista do produtor, que percebe o edifício a partir do exterior, o volume é um ser unitário, pois o objeto é o produto de um sujeito: para ele, o ser é uma totalidade (uma unidade). Do ponto de vista do proprietário, que percebe o edifício a partir do interior, o volume é um ser plural, uma vez que o objeto é um composto de partes reunidas pelo sujeito: para ele, o ser é um conjunto (uma pluralidade). Do ponto de vista do mercador, que percebe o edifício a partir do exterior, o vazio é um não-ser unitário, pois o espaço é o meio que envolve o volume: para ele, o não-ser é um complemento (um invólucro) do ser. Do ponto de vista do consumidor, que percebe o edifício a partir do interior, o vazio é um não-ser plural, pois o espaço é o conjunto de recipientes definidos pelo volume: para ele, o não-ser é um contentor (um receptáculo) que abriga o ser.

Considerando a análise sobre beleza de Aristóteles (ARISTÓTELES, apud PULS, 2006 p. 47), é possível considerar que as causas da beleza, formal, final, motora, material estão diretamente ligadas a nossa estrutura de conceituação do que é belo, utilizando as formas de avaliar que são agir, sentir, conhecer, desejar.

A dissertação se torna relevante na tentativa de buscar a construção pedagógica com alinhamento nas causas da beleza, avaliando as estruturas pedagógicas com o senso orgânico dos alunos no agir, sentir, conhecer e desejar.

A arquiteto busca saber do distanciamento entre o ser humano e os meios em que vive atuando de forma pluridisciplinar e realizando assim uma exegese para então reformular o espaços, tornando-os confortáveis e contextualizados com a realidade do homem da atualidade.

O docente assim como o arquiteto reconhece a distância entre ele e o aluno?, trazendo consigo embasamento cultural, filosófico, estrutural para construir sua aula, analisar seus alunos, a cultura em que vivem pois hoje existe a necessidade dos professores se contextualizarem com os alunos diante da distância que os separam. 
A arquitetura, como parte da história da humanidade, também se mostra presente nos passos individuais, constituindo linguagem aos espaços ocupados, reservando detalhes, segredos e condicionando pessoas a respirar arquitetura mesmo que de forma imperceptível. As avenidas, construídas por estes atos de conhecimento que se traduzem em grandes construções, casas, hospitais, escolas, ruínas de tempos passados, são os espaços, lugares de passagem, de socialização, de educação, de aprendizado. A aprendizagem que ocupa estas construções, também é condicionada pela beleza e tensão da arte de edificar, materializado no espaço, no tempo. Neste sentido, a experiência de aprendizagem também pode construir uma outra narrativa da sociedade. Isto porque a educação se dá na relação com o próximo e com as estruturas que este ocupa, as implicações disso são claras quando se trata de pensar a arquitetura. Seria a diversidade dos estudantes considerada nos projetos de aplicação da didática? Seriam os conteúdos pedagógicos arquitetados e concretizados a partir de uma premissa que considera a diversidade dos alunos? Segundo Araújo (1998, p. 44) diz:

[...] a escola precisa abandonar um modelo no qual se esperam alunos homogêneos, tratando como iguais os diferentes, e incorporar uma concepção que considere a diversidade tanto no âmbito do trabalho com os conteúdos escolares quanto no das relações interpessoais.

A relação da escola com o aluno, do mestre com o estudante deve transpassar o tecnicismo com fim em si mesmo, o construtivismo sem ser debatido e buscar além da construção técnica de conhecimento, emocionar, gerar interesse nos alunos, para que os mesmos busquem querer aprender a aprender.

\section{METODOLOGIA}

Abordagem Qualitativa com: Abordagens fenomenológico-hermenêuticas. Pesquisa básica Exploratória.

Na perspectiva de Paul Ricoeur, definem-se alguns critérios para a elaboração de um trabalho hermenêutico, dentre os quais destacamos o esforço pela fixação no sentido, bem como a necessidade de se interpretar os protocolos como um todo, como uma gestalt de sentidos interconectados, o que revela a potencialidade para múltiplas interpretações (Moustakas, 1994).

\section{RESULTADOS E DISCUSSÃO}

Os resultados encontrados no presente estudo sugerem que docentes precisam se contextualizar diante de seus discentes. O espaço da sala de aula é o espaço comunitário que, através das relações sociais, possibilita o relacionamento dos sujeitos e a construção de redes sociais. Isso indica que quem participa mais tende a ter um grau de contextualização maior, 
pois a participação permite um olhar crítico da realidade, um saber pronunciar-se a respeito de questões sociais como, por exemplo, conhecer a realidade do aluno. É possível afirmar, nesse sentido, que análise sociocultural seria a primeira condição para que a pessoa se aproprie da importância da contextualização.

\section{CONCLUSÕES}

O processo de contextualização caminha por uma nova ordem de pensamento e ação, longe de obter respostas imediatas para a problemática do distanciamento entre docente e discente no contexto educacional, apenas visualizando uma variedade de perspectivas e desafios para a efetiva implementação dessa contextualização.

Nesse sentido, as escolas devem criar ambientes acolhedores com ações que devem ser fortalecidas e regulamentadas no projeto pedagógico de cada instituição de ensino, proporcionando ambiente para as características individuais de cada cidadão e acreditando que os professores precisam se contextualizar diante das diferenças causadas pela modernidade, desde que se estruturem possibilidades, se estabeleçam estratégias na reordenação de práticas escolares e se reconsidere que a influência da redução de expectativas pode ser suficiente para determinar o insucesso escolar.

Esses espaços de educação devem promover relações recíprocas e dialéticas, eliminando o distanciamento entre alunos e professores. Assim, serão trabalhadas as reais necessidades e realizadas mediações no processo de aprendizagem com atividades desafiadoras, que estabeleçam conflitos interiores e promovam a contextualização entre alunos e professores.

\section{REFERÊNCIAS}

ARAÚJO, Ulisses Ferreira de. O déficit cognitivo e a realidade brasileira. In: AQUINO, Julio Groppa (org.): Diferenças e preconceito na escola: alternativas teóricas e práticas. 4. Ed. São Paulo: Summus Editorial, 1998.

ARISTÓTELES. Metafísica. (Trad.) Edson Bini. São Paulo: Edipro, 2012.

CARVALHO, Rosita Edler. Removendo Barreiras para a aprendizagem. 4. Ed. Porto Alegre: Mediação, 2002.

CORBUSIER, Le. Por uma Arquitetura. São Paulo: Perspectiva, 1989.

CORONA, Eduardo e LEMOS, Carlos A. C. Dicionário da Arquitetura Brasileira. São Paulo: Edart, 1972.

FINE, Steven. Art, History and the Historiography of Judaism in Roman

Antiquity.Boston: BRILL, 2013. 
LEMOS, Carlos A. C. O que é Arquitetura. São Paulo: Brasiliense, 1994.

MARCON, Karina; MACHADO, Juliana Brandão, Marie Jane Soares Carvalho (2012)

Arquiteturas Pedagógicas e Redes Sociais: Uma experiência no Facebook da pesquisadora. Disponível em: <http://br-ie.org/pub/index.php/sbie/article/download/1693/1454>. Acesso em: 10 ago. 2016.

MENEZES, Crediné. (2013) ARQUITETURAS PEDAGÓGICAS PARA A APRENDIZAGEM EM REDE NO CONTEXTO DO SEMINÁRIO INTEGRADOR | S. Encontrado em: <http://www.seer.ufrgs.br/index.php/renote/article/view/43645/27463>. Acesso em: 10 nov. 2016.

MORALES DE LOS RIOS Filho, Adolfo. Teoria e filosofia da arquitetura. Rio de Janeiro: Borsoi, 1960.

PULS. Mauricio. Arquitetura e Filosofia. Annablume, 2006.

RICOEUR, Paul. Arquitectura y Narratividad. In: THORNBERG, Josep Muntañola (Dir). Arquitectonics. Mind, Land \& Society. Barcelona: Edicions UPC, 2002.

RICOEUR, Paul. Teoria da interpretação: o discurso e o excesso de significação. Lisboa: Edições 70, 2000.

RICOEUR. Phénoménologie et Herméneutique in: VÁRIOS, Phénoménologie Heute, Grundlagen Und Methodenprobleme, Friburg-Muenchen, 1975.

THE TEN BOOKS ON ARCHITECTURE, Tr. de M. H. Morgan, Nova York: Dover, 1960; De Architectura, Tr. de F. Granger, Cambridge, Mass.: Harvard University Press, 1983. In: Pérez-Gómez, Alberto. 1994.

VIEIRA, Flávia. O professor como arquiteto da pedagogia na universidade. 2013. Disponível em: <http://www.epublicacoes.uerj.br/index.php/revistateias/article/view/24369/17347>. Acesso em: 03 set. 2016.

ZARAKIN, Andrés. Paredes que domesticam a arqueologia da arquitetura escolar capitalista; o caso de Buenos Aires. Campinas-SP: Centro de História da Arte e Arqueologia. 1FCH-Unicamp/Fapesp, 2002. 